\title{
Multiple Apical Periodontitis Influences Serum Levels of Cytokines and Nitric Oxide
}

\author{
Luciano Tavares Angelo Cintra, PhD, ${ }^{*}$ Renata Oliveira Samuel, MSc, * \\ Mariane Maffei Azuma, MSc, ${ }^{*}$ Ana Olívia Silva de Queiróz, DDS, ${ }^{*}$ Edilson Ervolino, PbD, ${ }^{\dagger}$ \\ Dóris Hissako Sumida, PhD, ${ }^{\dagger}$ Valéria Marçal Félix de Lima, PhD, ${ }^{\neq}$ \\ and João Eduardo Gomes-Filbo, $P$ bD*
}

\section{Ahstract}

Introduction: This study evaluated whether apical periodontitis (AP) in a single tooth or in multiple teeth affected serum levels of inflammatory mediators and influenced blood homeostasis. Methods: Thirty male Wistar rats were divided into 3 groups of 10 rats each: control group, healthy rats; $1 \mathrm{AP}$ group, rats with $A P$ in 1 tooth; and $4 A P$ group, rats with $A P$ in 4 teeth. After 30 days, the rats were anesthetized, and their blood was collected through cardiac puncture to quantify tumor necrosis factor alpha (TNF- $\alpha$ ), interferon gamma (IFN- $\gamma$ ), interleukin (IL)-6, IL-17, IL-23, and nitric oxide (NO) levels. The rats were then sacrificed by administering an anesthetic overdose. Their maxillary and mandibular molars were collected and processed for histologic analysis with hematoxylineosin and for immunohistochemical staining of the cytokines and NO-producing enzyme nitric oxide synthase. Results of these analyses were statistically analyzed; $P<.05$ was considered statistically significant. Results: Rats in the 1AP and 4AP groups showed increased IL-6, IL-17, IL-23, TNF- $\alpha$, IFN- $\gamma$, and NO synthase expression; inflammatory cell infiltration; and moderate bone resorption in affected teeth. Serum TNF- $\alpha$, IL-6, IL-17, and IL-23 levels were higher in rats in the 4AP group than in those in the control group $(P<.05)$. Serum NO levels were significantly lower in rats in the 1AP and 4AP groups than in those in the control group $(P<.05)$. Serum IFN- $\gamma$ levels were not different among rats in the 3 groups $(P>.05)$. Conclusions: These results suggested that AP affected blood homeostasis by altering the serum levels of inflammatory cytokines and NO. (J Endod 2016;42:747751)

\section{Key Words}

Apical periodontitis, cytokines, nitric oxide
The theory of focal infection, which was proposed in the early 20th century, suggests that pathogenic microorganisms causing dental infections can disseminate systemically and trigger systemic changes (1). Thus, the prescribed treatment for infected teeth was extraction (2). This theory was rejected because of the lack of scientific evidence (3). However, results of several recent studies on this topic indicate that dental infections such as apical periodontitis (AP) may potentiate the pathogenesis of autoimmune diseases, mainly by increasing inflammatory cell infiltration and serum cytokine levels (4-8).

The pathogenesis of AP is complex and involves inflammatory mediators that activate as well as inhibit inflammation (9). Pro- and antiinflammatory cytokines are produced by T-helper (Th) cells seeking to neutralize the pathogenic agents (10). Cells belonging to the Th1 lineage enhance the inflammatory process by secreting cytokines such as tumor necrosis factor alpha (TNF- $\alpha$ ) and interferon gamma (IFN- $\gamma$ ), which activate osteoclastogenesis and polymorphonuclear cells $(11,12)$. Cells belonging to the recently discovered Th17 lineage release cytokines such as interleukin (IL)-17 and IL-23 (13). Besides, in AP, Th17 cells and Th1 cells, which are also associated with increased bone resorption, are considered proinflammatory (14). IL-6 is produced by several cell types and is involved in acute-phase responses, B-cell maturation, and macrophage differentiation. In addition, IL-6 plays a dual role in Th1/Th2 differentiation (15).

Nitric oxide (NO) is an important inflammatory mediator involved in AP (16). NO is a ubiquitous free radical produced in various cells by a family of enzymes collectively known as NO synthases (NOSs) (17). Although the role of NO in AP is unknown, studies have shown that NO modulates the levels of proinflammatory cytokines such as IFN- $\gamma$ and TNF- $\alpha$ during the pathogenesis of AP $(18,19)$.

Our previous research showed that periodontal diseases induce systemic alterations. Although periodontal diseases or AP in a single tooth do not induce significant systemic changes, periodontal diseases or AP in 2 teeth alter some systemic parameters (5-7). Therefore, the present study evaluated the serum levels of TNF- $\alpha$, IFN- $\gamma$, IL-6, IL-17, IL-23, and NO in rats with AP in a single tooth or in multiple teeth.

\section{Experimental Design}

\section{Materials and Methods}

Three-month-old male Wistar rats (weight, 250-280 g) were housed in a temperature-controlled room $\left(25^{\circ} \mathrm{C}\right)$ with a 12-hour/12-hour dark/light cycle. The rats had ad libitum access to food and water. Experimental protocols of this study

From the Departments of *Endodontics and ${ }^{\dagger}$ Basic Sciences, Araçatuba Dental School, and ${ }^{\ddagger}$ Department of Clinic and Surgery and Animal Reproduction, Araçatuba Veterinary Medicine, Universidade Estadual Paulista, Araçatuba, São Paulo, Brazil.

Address requests for reprints to Dr Luciano Tavares Angelo Cintra, Department of Endodontics, Araçatuba Dental School, UNESP-Univ Estadual Paulista, R: José Bonifácio, 1193, Araçatuba, SP, Brazil. E-mail address: lucianocintra@foa.unesp.br

0099-2399/\$ - see front matter

Copyright (C) 2016 American Association of Endodontists.

http://dx.doi.org/10.1016/j.joen.2016.01.022 
were approved by the institutional ethics committee and were conducted in accordance with relevant guidelines (Ethics Committee on Animal Use, Universidade Estadual Paulista 2014-00108). The rats were divided into 3 groups of 10 rats each: control group, rats without AP; $1 \mathrm{AP}$ group, rats with AP in 1 tooth; and $4 \mathrm{AP}$ group, rats with $\mathrm{AP}$ in 4 teeth.

\section{Induction of Oral Infections}

Rats in the experimental groups were anesthetized by administering an intramuscular injection containing $13 \mathrm{mg} / \mathrm{kg}$ xylazine (Coopazine; Coopers Ltd Brazil, São Paulo, Brazil) and $87 \mathrm{mg} / \mathrm{kg}$ ketamine (Vetaset; Fort Dodge Animal Health Ltd, São Paulo, Brazil). AP was induced by exposing the pulp on the mesial surface of the first right maxillary molar of rats in the 1AP group and the first and second right maxillary and mandibular molars of rats in the 4AP group by using surgical round burs (Broca LN Long Neck; Maillefer, Dentsply Ind e Com Ltda, Petrópolis, RJ, Brazil). AP was induced by exposing the pulps for 30 days $(7,8)$.

\section{Assessment of Serum Levels of TNF- $\alpha$, IFN- $\gamma$, IL-6, IL-17, and IL-23}

After 30 days, venous blood samples $(5 \mathrm{~mL})$ were collected from the anesthetized rats through cardiac puncture after fasting the rats overnight for 8 to 12 hours. The blood samples were centrifuged immediately at $1800 \mathrm{~g}$ and $4^{\circ} \mathrm{C}$ for 15 minutes to obtain plasma, which was immediately stored at $-80^{\circ} \mathrm{C}$. Serum cytokine levels were assessed by performing capture enzyme-linked immunosorbent assays (ELISAs) using commercial kits (rat TNF ELISA set BD OptEIA, cat \#558535; BD Biosciences, San Diego, CA; rat IFN-gamma DuoSet, cat \#DY585; R\&D Systems, Inc, Minneapolis, MN; rat IL-6 ELISA set BD OptEIA, cat \#550319; BD Biosciences; rat IL-17A ELISA MAX Deluxe, cat \#437904; Biolegend, San Diego, CA; rat IL-23 ELISA kit, Uscn Life Science Inc, cat \#SEA384Ra; Wuhan, Hubei, China) according to the manufacturers' instructions.

\section{Assessment of Serum NO Levels}

Serum No levels were quantified using the Griess reaction as described by Guevara et al (20). For nitrate reduction, $100-\mu \mathrm{L}$ serum samples were incubated with nitrate reductase $(50 \mathrm{mU} / 100 \mu \mathrm{L}$ of the sample), nicotinamide adenine dinucleotide phosphate, and reduced tetrasodium salt hydrate diluted in $20 \mu \mathrm{mol} / \mathrm{L}$ Tris buffer for 30 minutes at room temperature. After reduction, the serum samples were incubated overnight with $900 \mu \mathrm{L}$ methanol:diethyl ether mixture $(3: 1 \mathrm{v} /$ v). The samples were then centrifuged (at $10,000 \mathrm{rpm}$ and $4^{\circ} \mathrm{C}$ for 10 minutes), and the supernatant was used for determining nitrite levels. For this, $50 \mu \mathrm{L} 6.5 \mathrm{~mol} / \mathrm{L} \mathrm{HCl}$ and $50 \mu \mathrm{L} 37.5 \mu \mathrm{mol} / \mathrm{L}$ sulfanilic acid were added to $200 \mu \mathrm{L}$ deproteinized supernatant samples. After incubation at $4^{\circ} \mathrm{C}$ for 10 minutes, $50 \mu \mathrm{L} 12.5 \mathrm{mmol} / \mathrm{L} \mathrm{N}-1$ naphthylethylenediamine was added, and the samples were incubated for 30 minutes at $4^{\circ} \mathrm{C}$. The samples were then centrifuged (at $10,000 \mathrm{rpm}$ and $4^{\circ} \mathrm{C}$ for 10 minutes), and their absorbance was measured at $540 \mathrm{~nm}$ by using a microplate reader (Labsystems, Midland, ON, Canada). A standard curve was generated using sodium nitrite concentrations ranging from $1-100 \mu \mathrm{mol} / \mathrm{L}$.

\section{Histopathological and Immunohistochemical Analyses}

After obtaining blood samples, the rats were sacrificed by administering an overdose of sodium thiopental $(150 \mathrm{mg} / \mathrm{kg})$ intraperitoneally. Their maxillary and mandibular molars were immediately dissected, post-fixed in neutral-buffered formalin for 18 hours (for fixing the samples and for preserving the antigenicity and tissues) (21), and decalcified in 17\% buffered EDTA ( $\mathrm{pH}=8$; Sigma-Aldrich, St Louis, M0). The first molar was sectioned semiserially (thickness $=4 \mu \mathrm{m}$ ) along its longitudinal axis (21). The sections were stained with hematoxylin-eosin for histologic analysis, or they were used for performing immunohistochemical staining with an indirect immunoperoxidase technique by using primary antibodies against TNF- $\alpha$, IFN- $\gamma$, IL-6, IL-17, IL-23, and NOS (Santa Cruz Biotechnology, Santa Cruz, CA). Immunohistochemical staining was performed according to a protocol described previously (21).

The intensity of inflammation was graded as follows: no inflammation (score 1: 0 or few inflammatory cells), mild inflammation (score 2: $<25$ inflammatory cells), moderate inflammation (score 3: 25-125 inflammatory cells), and severe inflammation (score 4: $>125$ inflammatory cells). Semiquantitative immunolabeling of TNF- $\alpha$, IFN- $\gamma$, IL6, IL-17, IL-23, and NOS was performed by a certified histologist who was blinded to the treatments. Three histologic sections were used for each animal, and positive immunoreactivity (IR) was defined as a brownish color in the cytoplasm of the cells and extracellular matrix. Because immunolabeling of both the cells and the extracellular matrix is of great importance for our study, we performed semiquantitative analysis, which provides information on the numbers of immunoreactive cells and immunolabeling intensity of the extracellular matrix. The scores were assigned as follows (22): 0, complete absence of immunoreactive cells; 1 (low IR), a few immunoreactive cells and weak labeling of the extracellular matrix (approximately one quarter of the immunoreactive cells); 2 (moderate IR), a moderate number of immunoreactive cells and moderate labeling of the extracellular matrix (approximately one half of the immunoreactive cells); and 3 (high IR), a large number of immunoreactive cells and strong labeling of the extracellular matrix (approximately three quarters of the immunoreactive cells).

\section{Statistical Analysis}

Statistical analyses and data tabulation were performed using SigmaPlot software (Systat Software Inc, San Jose, CA). Nonparametric data were analyzed by performing multiple comparisons with the KruskalWallis test followed by the Dunn test. Parametric data were analyzed by performing analysis of variance followed by the Tukey test. The level of significance was set at $5 \%$.

\section{Results \\ Serum Levels of TNF- $\alpha$, IFN- $\gamma$, IL-6, IL-11, and IL-23}

Serum levels of TNF- $\alpha$, IFN- $\gamma$, IL-6, IL-17, and IL-23 are shown in Table 1 . Serum levels of TNF- $\alpha$, IL-6, IL-17, and IL-23 were significantly higher in rats in the 4AP group than in rats in the control group $(P<.05)$. Although rats in the 1AP group showed an increase in the serum levels of most cytokines compared with rats in the control group, the difference was not statistically significant $(P>.05)$. Serum IFN- $\gamma$ levels were not different among rats in the 3 groups $(P>.05)$. Moreover, no difference was observed between rats in the 1AP and 4AP groups with respect to the levels of TNF- $\alpha$, IL-6, IL-17, and IL-23 $(P>.05$, Table 1)

\section{Serum Levels of NO}

AP decreased serum NO levels in rats $(P<.05$, Table 1$)$. Serum NO levels were significantly lower in rats in the $1 \mathrm{AP}$ and $4 \mathrm{AP}$ groups than in rats in the control group $(P<.05)$. However, no significant difference was observed in serum NO levels between rats in the 1AP and 4AP groups $(P>.05)$. 
Basic Research-Biology

TABLE 1. Serum Levels of Cytokines (in $\mathrm{pg} / \mathrm{mL}$ ) and Nitric Oxide (in $\mu \mathrm{mol} / \mathrm{L}$ )

\begin{tabular}{lccc}
\hline & & Groups * $^{*}$ & 1AP \\
\cline { 2 - 4 } Inflammatory mediators & Control group & 4AP \\
\hline Kruskal Wallis (mean, min-max values) & & $29.21(18.1-36.7)^{\mathrm{ab}}$ & $94.27(43.4-158.0)^{\mathrm{b}}$ \\
TNF- $\alpha$ & $25.53(15.3-26.9)^{\mathrm{a}}$ & $45.48(35.9-78.7)^{\mathrm{a}}$ & $40.72(35.9-50.2)^{\mathrm{a}}$ \\
IFN- $\gamma$ & $40.72(35.9-45.4)^{\mathrm{a}}$ & $53.24(24.1-169.8)^{\mathrm{ab}}$ & $224.00(67.4-463.8)^{\mathrm{b}}$ \\
IL-6 & $53.36(32.4-113.4)^{\mathrm{a}}$ & $15.18(10.5-20.7)^{\mathrm{ab}}$ & $37.46(27.6-52.7)^{\mathrm{b}}$ \\
IL-23 & $13.25(9.3-19.7)^{\mathrm{a}}$ & $96.45 \pm 0.11^{\mathrm{ab}}$ & $96.6 \pm 0.21^{\mathrm{b}}$ \\
ANOVA (mean \pm SD) & $96.44 \pm 0.08^{\mathrm{a}}$ & $6.56 \pm 2.45^{\mathrm{b}}$ & $5.58 \pm 2.10^{\mathrm{b}}$ \\
IL-17 & $11.09 \pm 5.15^{\mathrm{a}}$ & & \\
NO &
\end{tabular}

$1 \mathrm{AP}$, rats with apical periodontitis in 1 tooth; 4AP, rats with apical periodontitis in 4 teeth; IFN- $\gamma$, interferon gamma; IL, interleukin; NO, nitric oxide; TNF- $\alpha$, tumor necrosis factor alpha.

*Different letters indicate significant statistical differences in lines $(P<.05)$.

\section{Histologic and Immunohistochemical Analyses}

Histologic analyses of tooth sections of rats in the experimental groups are shown in Figure $1 A-U$. Tooth sections of rats in both the $1 \mathrm{AP}$ and $4 \mathrm{AP}$ groups showed necrosis and AP at 30 days after pulp exposure. Moreover, tooth sections of rats in these groups predominantly showed moderate inflammatory infiltration of mononuclear cells (score 3). Tooth sections of rats in the control group showed no inflammation (scored 0 ). The evaluation of cytokines predominantly showed moderate immunolabeling for TNF- $\alpha$, IFN- $\gamma$, IL-6, IL-17, IL-23, and NO in the tooth sections of rats in the 1AP and 4AP groups, with no significant difference between the 2 groups. Sections of healthy teeth of rats in the control group showed complete absence of immunoreactive cells (score 0). The highest IR was observed in the tooth sections of rats in the 1AP and 4AP groups compared with those of rats in the control group $(P<.05$, Fig. 1$)$.

\section{Discussion}

This study evaluated whether AP in a single tooth or in multiple teeth altered the serum levels of inflammatory mediators. Our results showed an increase in the serum levels of IL-6, IL-17, IL-23, and TNF$\alpha$ in rats with AP lesions in multiple teeth. In contrast, serum NO levels decreased in rats with AP lesions in a single tooth or in multiple teeth.

Increased serum levels of proinflammatory cytokines in rats with AP confirm the hypothesis that endodontic infections adversely affect systemic health similar to periodontal diseases, which is consistent with that reported by several studies (23-25). In our previous studies $(5-7)$, we showed that periodontal diseases in a single tooth exerted an inflammatory response similar to AP in a single tooth (ie, they did not significantly alter the serum levels of inflammatory cytokines) (5-7). In contrast, AP associated with periodontal disease, affecting 2 teeth, altered the numbers of inflammatory cells and levels of proinflammatory mediators in the blood (5-7).

An AP-induced increase in the numbers of inflammatory cells and serum levels of cytokines can affect the balance of the bloodstream. Therefore, against another pathogenic agent or pathological process, there is exacerbating inflammation in regions distant from the origin, leading to uncontrolled systemic inflammation (26). Although the function of inflammation is to protect host organisms from pathogenic agents, excessive inflammation leads to the loss of specificity and aggressively affects healthy tissues (26). For example, inflammation induced by periodontal diseases stimulates proinflammatory mediators, which, in turn, enhance the pathogenesis of autoimmune diseases such as diabetes, lupus, and rheumatoid arthritis (25).

TNF- $\alpha$ and IL- 6 stimulate a proinflammatory response by recruiting more inflammatory cells and mediators to restrict a pathogenic agent or a pathological process (11). Once in the bloodstream, TNF$\alpha$ and IL- 6 can be attracted by chemotaxis to sites with advanced or incipient inflammatory processes, enabling inflammation, and may cause exaggerated responses that damage healthy tissue (27). Similarly, a previous study showed that 20 - to 40 -year-old patients with AP were predisposed to cardiovascular diseases and showed a significant increase in the serum levels of IL-1, IL-2, and IL-6 (4).

Th17 cells function like Th1 cells in AP and systemic diseases and exacerbate AP-associated inflammation, including bone resorption, painful symptoms, and flare-up $(14,28)$. In a previous study, we showed that dental infections (AP and periodontal diseases) in 2 teeth increase serum levels of IL-17 and neutrophils (6). In the present study, serum levels of IL-17 and IL-23 increased in rats with AP in multiple teeth and were associated with bone resorption. Both IL-17 and IL23 are involved in the pathogenesis of autoimmune diseases and act along with other inflammatory mediators to enhance pathological processes $(28,29)$.

In the present study, no difference was observed in serum IFN- $\gamma$ levels among rats in the 3 groups. The biological effects of IFN- $\gamma$ in AP include activation of leukocytes such as T and B cells, macrophages, and natural killer cells (30) and an increase in local osteoclastic activity $(12,31)$. Our analysis was performed 30 days after AP induction when the disease was in the chronic phase; this may explain the lack of differences between rats in the groups. However, further studies are needed to determine whether AP temporarily increases the serum levels of IFN- $\gamma$ because it is present in local tissues.

Another important observation of this study was the reduction in serum NO levels in rats with AP irrespective of the number of affected teeth. NO is synthesized by NOS from L-arginine. However, the role of NO in AP is unclear. The suppression of NO by aminoguanidine accelerates the treatment of AP (32). However, because IFN- $\gamma$ and TNF- $\alpha$ stimulate NO production, low concentrations of NO may increase the production of these proinflammatory cytokines (which are also involved in osteoclastogenesis), thus exacerbating inflammation $(18,19)$.

In the present study, NO was detected in AP tissue despite its reduced levels in the blood. A recent study showed that serum levels of NO and its metabolites in patients with periodontal diseases increased locally at the site of infection and decreased in the blood (24).

Approximately $70 \%-90 \%$ of NO and its metabolites in the blood are derived from endothelial physiological activity (33). Given the importance of inter-relationships between different mediators involved in the pathogenesis of periapical lesions, perhaps AP may promote an imbalance in the vascular homeostasis system, which can be stimulated by other inflammatory mediators (34).

Previous studies have shown that patients with periodontal diseases show impaired endothelium-dependent vasodilatation $(34,35)$ that may be associated with decreased NO production by the endothelium (34). Thus, an increase in NO production may occur locally in tissues with periodontal diseases and may not be reflected in the systemic levels of NO (24). 


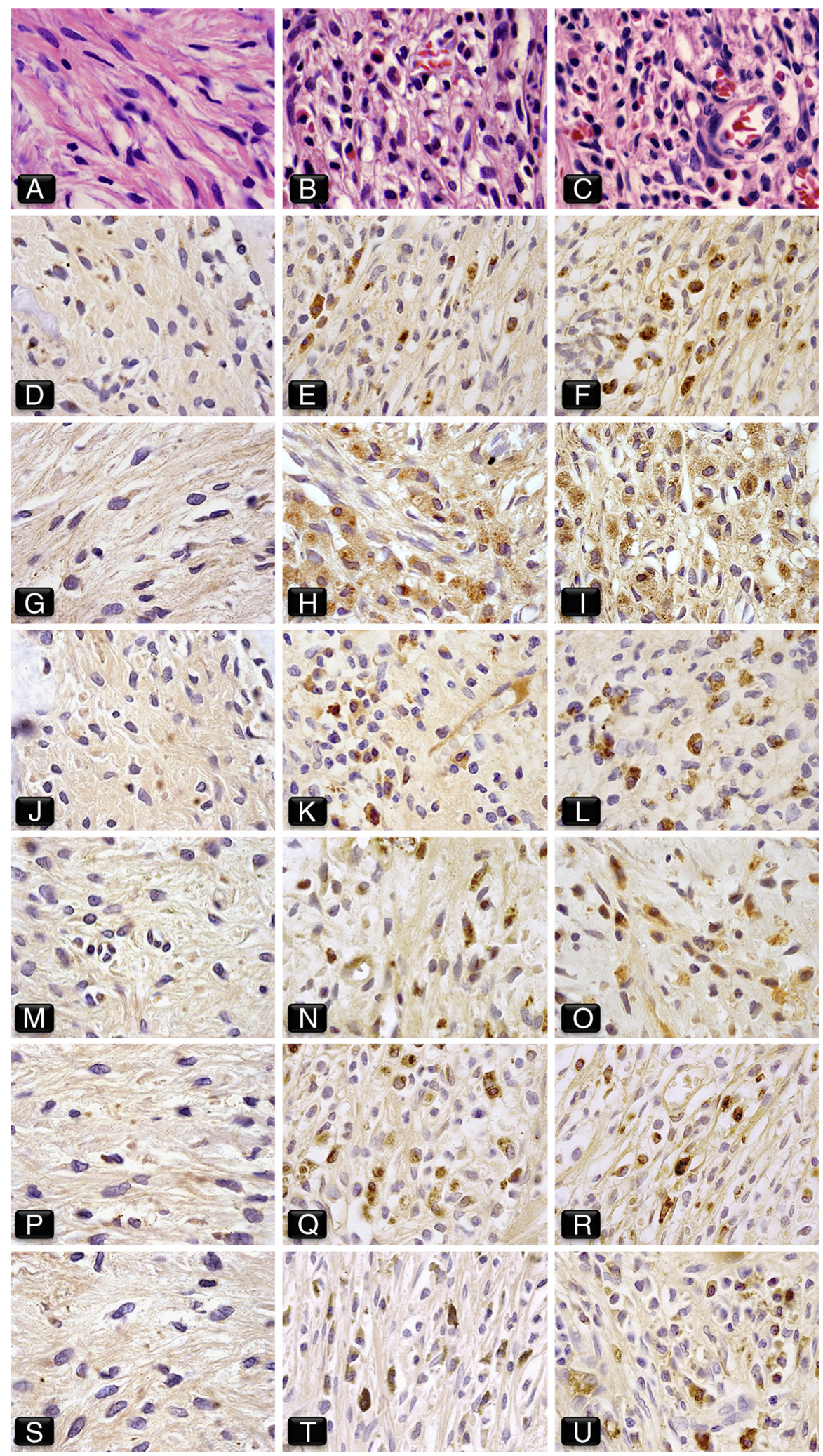

Figure 1. Representative photographs of $(A-C)$ histologic and $(D-O)$ immunohistochemical analyses of induced periapical lesions and healthy tooth tissues of rats. (A) Healthy tissue of rats in the control group without inflammation in the apical region (hematoxylin-eosin staining, $\times 1000)$. $(B$ and $C)$ Predominance of mononuclear cells in the inflammatory infiltrates of AP lesions (hematoxylin-eosin staining, $\times 1000)$ in $(B)$ rats in the $1 \mathrm{AP}$ group and $(C)$ rats in the 4AP groups. $(D-F)$ In situ TNF- $\alpha$ expression in rats in the $(D)$ control, $(E) 1 \mathrm{AP}$, and $(F)$ in 4AP groups. $(G-I)$ In situ IFN- $\gamma$ expression in rats in the $(G)$ control, $(H) 1 \mathrm{AP}$, and (I) 4AP groups. (J-L) In situ IL-6 expression in rats in the $(J)$ control, $(K) 1 \mathrm{AP}$, and $(L)$ 4AP groups. $(M-O)$ In situ IL-17 expression in rats in the $(M)$ control, $(N)$ $1 \mathrm{AP}$, and $(O)$ 4AP groups. $(P-R)$ In situ IL-23 expression in rats in the $(P)$ control, $(Q) 1 \mathrm{AP}$, and $(R)$ 4AP groups. $(S-U)$ In situ NOS expression in rats in the $(S)$ control, $(T) 1 \mathrm{AP}$, and $(U)$ 4AP groups. Magnification for $A-O: \times 1000$. 
However, further studies are needed to elucidate mechanisms underlying the reduction of serum NO levels and its effect on systemic health.

\section{Conclusion}

Our results indicate that AP affects blood homeostasis by increasing the numbers of TNF- $\alpha$-, IL-6-, IL-17-, and IL-23-secreting cells and by decreasing the levels of NO. Our results also indicate that an increase in the number of AP-affected teeth increases the changes in the serum levels of inflammatory mediators.

\section{Acknowledgments}

Supported by FAPESP (grant no. 2013/23358-8). The authors deny any conflicts of interest related to this study.

\section{References}

1. Miller WD. The human mouth as a focus of infection. Dent Cosmos 1891:33: $689-713$.

2. Darling BC. Roentgen-ray indications for tooth extraction the medical roentgenologist offers an impartial survey for the physician, the dentist, and the patient. J Dent Res 1919;1:391-412.

3. Newman HN. Focal infection. J Dent Res 1996;75:1912-9.

4. Cotti E, Dessì C, Piras A, et al. Association of endodontic infection with detection of an initial lesion to the cardiovascular system. J Endod 2011;37:1624-9.

5. Cintra LT, da Silva Facundo AC, Prieto AK, et al. Blood profile and histology in oral infections associated with diabetes. J Endod 2014;40:1139-44.

6. Cintra LT, Samuel RO, Azuma MM, et al. Apical periodontitis and periodontal disease increase serum IL-17 levels in normoglycemic and diabetic rats. Clin Oral Investig 2014; 18:2123-8.

7. Cintra LT, Samuel RO, Facundo AC, et al. Relationships between oral infections and blood glucose concentrations or HbA1c levels in normal and diabetic rats. Int Endod J 2014; 47:228-37.

8. Astolphi RD, Curbete MM, Chiba FY, et al. Periapical lesions decrease insulin signaling in rat skeletal muscle. J Endod 2015;41:1305-10.

9. Araujo-Pires AC, Francisconi CF, Biguetti CC, et al. Simultaneous analysis of T helper subsets (Th1, Th2, Th9, Th17, Th22, Tfh, Tr1 and Tregs) markers expression in periapical lesions reveals multiple cytokine clusters accountable for lesions activity and inactivity status. J Appl Oral Sci 2014;22:336-46.

10. Reiner SL. Development in motion: helper T cells at work. Cell 2007;129:33-6.

11. Martinho FC, Chiesa WM, Leite FR, et al. Correlation between clinical/radiographic features and inflammatory cytokine networks produced by macrophages stimulated with endodontic content. J Endod 2012;38:740-5.

12. de Carvalho Fraga CA, Alves LR, de Sousa AA, et al. Th1 and Th2-like protein balance in human inflammatory radicular cysts and periapical granulomas. J Endod 2013 $39: 453-5$.

13. Bettelli E, Korn T, Oukka M, Kuchroo VK. Induction and effector functions of T(H) 17 cells. Nature 2008;453:1051-7.

14. Marçal JR, Samuel RO, Fernandes D, et al. T-helper cell type 17/regulatory T-cel immunoregulatory balance in human radicular cysts and periapical granulomas. J Endod 2010;36:995-9.
15. Diehl S, Rincón M. The two faces of IL-6 on Th1/Th2 differentiation. Mol Immunol 2002;39:531-6.

16. Silva MJ, Sousa LM, Lara VP, et al. The role of iNOS and PHOX in periapical bone resorption. J Dent Res 2011;90:495-500.

17. Hibbs JJ, Tainton R, Vavrin Z. Macrophage cytoxity: role for L- arginine deaminase activity and imino nitrogen oxidation to nitrite. Science 1987;235:473-6.

18. Ralston SH, Ho LP, Helfrich MH, et al. Nitric oxide: a cytokine-induced regulator of bone resorption. J Bone Miner Res 1995;10:1040-9.

19. Kabashima H, Nagata K, Maeda K, Iijima T. Interferon-gamma-producing cells and inducible nitric oxide synthase-producing cells in periapical granulomas. J Oral Pathol Med 1998;27:95-100.

20. Guevara I, Iwanejko J, Dembińska-Kieć A, et al. Determination of nitrite/nitrate in human biological material by the simple Griess reaction. Clin Chim Acta 1998; 274:177-88.

21. Gomes-Filho JE, Wayama MT, Dornelles RC, et al. Effect of raloxifene on periapical lesions in ovariectomized rats. J Endod 2015;41:671-5.

22. De Almeida J, Ervolino E, Bonfietti LH, et al. Adjuvant therapy with sodium alendronate for the treatment of experimental periodontitis in rats. J Periodontol 2015;86: 1166-75.

23. Joshipura KJ, Wand HC, Merchant AT, Rimm EB. Periodontal disease and biomarkers related to cardiovascular disease. J Dent Res 2004;83:151-5.

24. Andrukhov 0 , Haririan $\mathrm{H}$, Bertl K, et al. Nitric oxide production, systemic inflammation and lipid metabolism in periodontitis patients: possible gender aspect. J Clin Periodontol 2013;40:916-23.

25. Jeffcoat MK, Jeffcoat RL, Gladowski PA, et al. Impact of periodontal therapy on general health: evidence from insurance data for five systemic conditions. Am J Prev Med 2014;47:166-74.

26. Bian Z, Guo Y, Ha B, et al. Regulation of the inflammatory response: enhancing neutrophil infiltration under chronic inflammatory conditions. J Immunol 2012; 188:844-53.

27. D'Aiuto F, Parkar M, Andreou G, et al. Periodontitis and systemic inflammation: control of the local infection is associated with a reduction in serum inflammatory markers. J Dent Res 2004:83:156-60.

28. Kramer JM, Gaffen SL. Interleukin-17: a new paradigm in inflammation, autoimmunity, and therapy. J Periodontol 2007:78:1083-93.

29. Azadegan-Dehkordi F, Bagheri N, Shirzad H, Rafieian-Kopaei M. The role of Th1 and Th17 cells in glomerulonephritis. J Nephropathol 2015;4:32-7.

30. Chen CP, Hertzberg M, Jiang Y, Graves DT. Interleukin-1 and tumor necrosis factor receptor signaling is not required for bacteria-induced osteoclastogenesis and bone loss but is essential for protecting the host from a mixed anaerobic infection. Am J Pathol 1999:155:2145-52.

31. Colić M, Gazivoda D, Vucević D, et al. Proinflammatory and immunoregulatory mechanisms in periapical lesions. Mol Immunol 2009;47:101-13.

32. Farhad AR, Razavi SM, Nejad PA. The use of aminoguanidine, a selective inducible nitric oxide synthase inhibitor, to evaluate the role of nitric oxide on periapical healing. Dent Res J 2011;8:197-202.

33. Rhodes P, Leone AM, Francis PL, et al. The l-arginine:nitric oxide pathway is the major source of plasma nitrite in fasted humans. Biochem Biophys Res Commun 1995; 209:590-6.

34. Amar S, Gokce N, Morgan S, et al. Periodontal disease is associated with brachial artery endothelial dysfunction and systemic inflammation. Arterioscler Thromb Vasc Biol 2003;23:1245-9.

35. Higashi Y, Goto C, Jitsuiki D, et al. Periodontal infection is associated with endothelial dysfunction in healthy subjects and hypertensive patients. Hypertension 2008;51: 446-53. 